\title{
Applicability of Bus Rapid Transit to Corridors with Intermediate Levels of Transit Demand
}

\author{
Graham N. Carey \\ Lane Transit District, Eugene, Oregon
}

\begin{abstract}
Bus Rapid Transit (BRT) has the potential to bridge the gap between conventional rubber-tired transit operations and rail systems. Based on relatively low-cost, proven technology, BRT is gaining acceptance in many communities around the world that are endeavoring to provide high-quality transit service. While proposed applications of this new mode vary considerably, some conditions may be more appropriate than others. This article explores, from the point of view of the practitioner, some of the benefits and drawbacks of BRT.

\section{Introduction}

As communities grow, transportation planners are faced with an increasing dilemma. There is a need for increased personal mobility, but there is a dwindling pool of funds and growing public backlash against new road construction.

While transit is purported to be the solution, existing forms of transit service are either inappropriate in most environments or considered unacceptable alternatives to the private automobile by a large portion of the population. Conventional bus services, the workhorses of the transit industry over the last half decade, have failed to keep up with the changing desires and needs of the traveling public. In recent years, light rail transit (LRT) has been extremely successful in capturing the
\end{abstract}


imagination of the traveling public. This mode does, however, require a relatively high level of patronage to support the service and is cost-prohibitive in many corridors. As it is unlikely that we will be able to develop a sufficient number of railbased systems to meet the desires of the traveling public, we need to identify a means of providing an affordable higher level of transit service.

Over the last 30 years, transit providers have experimented with enhanced bus services that provide a higher level of service. These services, which range in form from express operations to busway projects, are viable alternatives to the private automobile. Few operations have been successful in emulating the appeal of their rail counterpart. In the late 1960s and 1970s, a number of transit systems attempted to bridge the gap between conventional bus and rail systems. These systems, referred to at the time as BRT, primarily relied on the provision of bus-only lanes on freeways and were perhaps better described as "bus highway" systems.

Since their introduction, the growth in private automobile use has produced increasing pressure for additional lane capacity, resulting in many bus facilities being converted to high-occupancy vehicle (HOV) facilities. This has further diminished the effectiveness of the service and has in a number of cases resulted in their termination.

What is it about rail-based systems that make them preferable to the traveling public? Is it their simplicity, directness of routes, look, permanence, ease of use, or speed? The answer is all of the above. To further complicate the matter, when we mention "rail," what do we mean? For most of us the term means steel wheel on a rail. That being the case, how do we characterize the rubber-tired subway systems demonstrated in Montreal and Paris?

On a purely mathematical level, Nobel Prize-winning economist Daniel McFadden used consumer choice theory to illustrate that commuters will react, all things being equal, to a high-quality bus-based system the same as they would to a rail rapid transit system (e.g., BART). However, this has not been the case in practice. Many attempts have been made to emulate rail-based systems using a rubber-tired vehicle. These attempts have not realized the success of similar railbased systems. There would appear to be something missing, which is probably not mathematically quantifiable. 
If the bus mode is to be viewed by the traveling public as being comparable to rail-based services such as LRT, it must not only provide the same level of convenience and service but also emulate those more subjective attributes of the mode, such as its look and feel.

\section{What Is BRT?}

By definition BRT is a rubber-tired transit system that mimics the positive components of a rail-based system. We could say "like" rail rather than light rail. Before defining the components of a BRT system it is appropriate to compare conventional bus with its rail counterpart. Table 1 compares the positive and negative aspects of both modes. While bus offers flexibility in routing and is cost effective, its routing tends to be complex and it has a poor public image. Rail, while considered inflexible, benefits from a positive public image, is seen as easy to understand, and is permanent.

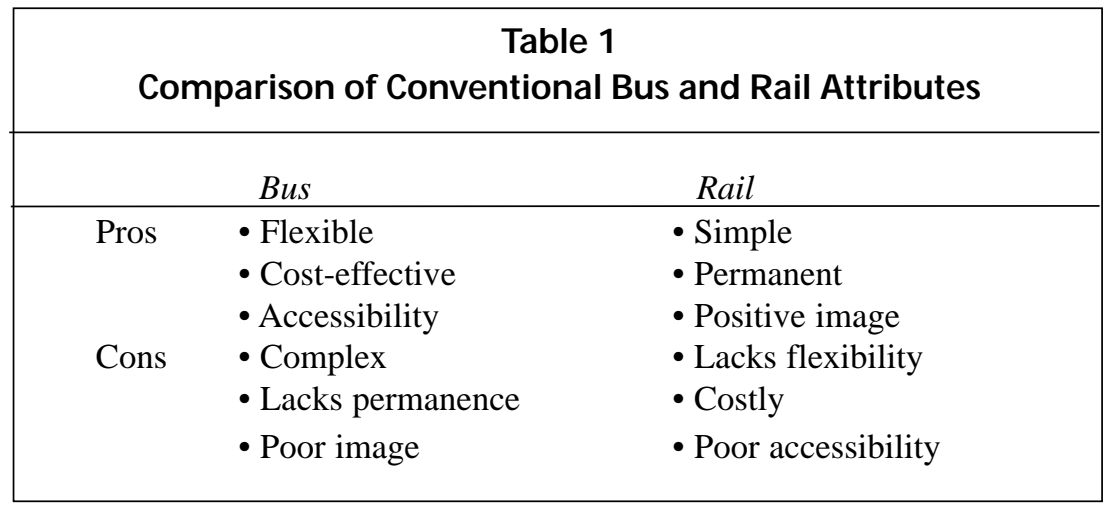

The relative newness of the BRT concept has resulted in varying definitions. Typically, BRT is described as combining "the quality of rail transit with the flexibility of the bus. BRT vehicles operate over a variety of travel ways and are likely to include exclusive rights-of-way, traffic signal priority, off-vehicle fare collection, low floor vehicles. ..." While all the definitions list possible attributes that can be associated with a BRT system, none mandate which ones are essential to a system and which are optional. The vagueness of the definition is not without good reason. With the promise of federal attention and possible funding assistance, all transit agencies undertaking enhanced bus systems wish 
the definition to be all-encompassing. This has lead to a generic definition, which will only serve to dilute the overall thrust of BRT, producing a series of operating examples that fail to illustrate the true benefits of the mode.

The key distinguishing attribute between an express bus service and a BRT system is the exclusive right-of-way. Without an independent right-of-way along most of the route's path, the service offered by BRT will be severely restricted. It will not provide reduced travel time and increased reliability to lure new riders. As most proposed BRT systems will be operating in existing built-up urban environments, identifying and acquiring exclusive rights-of-way are particularly challenging. However, without them the BRT service is merely an express bus operation. Exclusive rights-of-way demonstrate a commitment to the community and its federal partners to the development of a high-quality permanent system. The formulation of a more specific definition of BRT is imperative, as it will shape future projects.

A more apt definition of BRT would be:

A flexible mode that integrates capital and operational improvements to create a faster, higher-quality mode of travel than conventional bus service. BRT projects should include, at minimum, exclusive rights-of-way on at least a major part of the corridor. In addition, BRT should incorporate the following attributes:

- Priority at intersections: Queue jumpers and other transit priority measures at intersections can reduce transit travel time.

- Signal priority: BRT buses would receive preferential treatment at signalized intersections to reduce travel time.

- Improved passenger boarding facilities: BRT stations should have permanence and substance. Stations should also be integrated into commercial developments and neighborhoods wherever possible.

- Coordination with land-use planning: BRT system design and land-use planning should be coordinated to provide high-quality transit service in proximity of high-intensity land uses.

- Limited stations: Station spacing is lengthened to reduce travel time.

- Prepaid fares: Elimination of onboard fare collection reduces dwell time at stations. 
- Level boarding: Designing the passenger boarding area at the same height as the bus reduces dwell time at stations and provides easy access for all users.

- Unique vehicles: BRT vehicles should be designed to meet the functional requirements of the BRT systems. The BRT system should endeavor to develop a unique identity whereby the look of its vehicles supports the overall image of the operation.

- Direct routing: Simple, easy-to-understand route structures with termini at major generators.

In addition, BRT systems should also strive to incorporate Intelligent Transportation Systems (ITS) technology as much as practically possible to increase reliability and passenger expectations.

\section{Why BRT?}

BRT is an appropriate choice for many corridors because it:

- protects rights-of-way;

- utilizes existing resources;

- acts as a pathfinder; and

- garners political/community support.

\section{Protecting Rights-of-Way}

The rate of growth in travel demand is exceeding the rate at which road space can be made available. Facilities designed to accommodate 20 to 30 years of traffic growth are reaching saturation well before their time. As many communities have discovered, this race to provide enough road capacity to accommodate a rapidly expanding demand for unrestricted private vehicle use is futile. Counterintuitively, some researchers (Arnott and Small 1994) have argued that the construction of additional road capacity may, in fact, increase levels of congestion. Even if this premise is not accepted, at some point the provision of additional road capacity will be impossible-whether for reasons of land availability, engineering feasibility, or political unwillingness. When gridlock is impending, attention is usually directed toward transit to provide 
the solution. Within the confines of the existing right-of-way, it is difficult for transit to provide any improvement, as transit vehicles are subject to the same traffic conditions as other modes. The only solution is to retrofit exclusive transit facilities, which requires the commandeering of existing travel lanes or the acquisition of additional rights-of-way, both of which may be politically objectionable.

To avoid such a situation, it is critical that long-range plans be developed. These plans must identify future transit corridors and take steps to protect rightsof-way so they can be utilized by transit in the future. Identification of the specific transit mode to use the tract of land is of little importance at this stage. The important point is that this right-of-way be available when needed. The old transit adage "great transit cities don't just evolve, they are planned that way" still holds true today.

Identification and acquisition of suitable rights-of-way for transit before conditions of unacceptable congestion occur can be undertaken to benefit the purchaser. Generally in growing communities, properties along less-congested corridors tend to be residential rather than commercial, as the high travel volumes usually attract commercial developers. As the corridor becomes more highly trafficked, properties become less desirable as residences and usually are rezoned to a higher use, thereby increasing their value. Without the prospect of transit these commercial properties tend to be developed in a way that is less transit-supportive, making it difficult for transit passengers to conveniently access the development.

Identification of future transit corridors tends to reduce the urgency of purchase of the property, allowing for more thorough negotiation with the property owner.

\section{Utilizing Existing Resources}

Over a long period, a considerable amount of time and money has been spent in developing processes and structures that, together with the purchase of specialized equipment, are suitable for the particular mode. With the introduction of a new mode, new systems will need to be developed, new equipment purchased, and new maintenance facilities constructed. 
The transition from one technology to another may require a complete reassessment of operational and staffing needs. Considerable staff training is involved, and new staff with different skills will need to be employed. These staff changes should be negotiated with organized labor groups to ensure a smooth transition.

To maintain stability within the transit operating authority, it is important to utilize available resources to their full extent and build on the strengths of the organization rather than disregard present structures and introduce an all-new system.

The BRT system, therefore, allows the operating authority to "consume" the assets (i.e., get the most use out of them) while positioning itself for more advanced modes/operating systems.

\section{Acting as a Pathfinder}

It is not uncommon for the development of a rail-based system to exceed 10 years. The estimation of future passenger demand for a service that is only to be introduced within a decade is, at best, an imprecise science. Using results of new systems that have been initiated during the last 10 years, we have been able to refine the process to more accurately reflect likely conditions. Since the demographics of each corridor vary, the transferability of data from other systems can provide some indication of likely events, but it is far from precise. BRT systems, with their short "gestation period," allow operators to validate passenger demand for a higher level of service, thus reducing the risk of service failure. BRT provides an opportunity to partly replicate service and operational characteristics of a higher mode. If prerequisite thresholds of demand for the higher mode are developed, then its introduction will be better assured of success.

With the introduction of a higher mode, such as LRT, a number of services associated with the mode must be fully operational from the onset. These services include fare collection, traffic signal priority, electrical supply, and communications. Ensuring complete operation of these services at the beginning is a difficult task, and their failure can lead to a poor perception of the new system.

Introducing aspects of a future service as part of the BRT operation allows the provider an opportunity to fine-tune the components of the system and to 
concentrate on a limited number of key components. When the higher mode is introduced, many of the components will be fully operational and fewer "teething" problems will occur.

\section{Garnering Political/Community Support}

All indications from the Federal Transit Administration are that local communities will have to provide a higher proportion of the funding for their major capital projects. To date, the larger capital projects have benefited from copious financial contributions from the federal government. With nonlocal funds bearing the lion's share of the financial commitment, those community members not directly impacted have tended to be indifferent to the project. However, this increased demonstration of financial support by the community will attract a far higher level of scrutiny. Exacerbating the situation will be the perception that one large capital project is consuming funds that could be distributed over the whole service area.

At the community level, the leap from one technology to another can cause concern. In communities with an engaged citizenry, there will be a variety of solutions presented to address the transportation need. These solutions are likely to vary from belief that there is no problem and resultantly no need to do anything to a feeling that there is an immediate need and a high-technology solution is appropriate.

Increasingly, the community is becoming more involved in the planning of its neighborhoods. Thus, proposals must be justifiable and defendable and all appropriate alternatives should be thoroughly evaluated before recommending a direction forward. This increased scrutiny means that any attempt to force an inappropriate solution will undoubtedly be met with vociferous comment.

BRT provides the opportunity to develop a high-quality mass transit system in a stepwise, incremental manner. Lower-cost investments can be made in the system accordingly. Time should be allowed for the benefits of the improvement to accrue and ridership to respond. Then further investments can be made. Metro Rapid in Los Angeles is good a example of a community that is using this strategy to develop its BRT system.

From a community standpoint, this is a fiscally responsible approach. The BRT system is seen as a logical step forward-by enhancing what is already in existence, without overextending the financial means of the community. 
This approach also provides a logical process that addresses the needs of the proponents of rail-based systems without compromising the future need for a higher mode. In addition, BRT allows time for more in-depth debates as to the appropriate timing of a rail-based system.

\section{Why Not BRT?}

Whenever a new innovation becomes available, there is a tendency to try to apply it to every situation as if it were the panacea to all transit problems. On the one hand, it is encouraging that a new mode is considered, thus extending our toolbox of available techniques. On the other hand, the inappropriate application of a mode is likely to have a negative effect on the industry and impact the introduction in more suitable environments. Clearly, a thorough, unbiased assessment of the alternatives should be undertaken during the project development stage to ensure that the most appropriate mode is selected. The adage of "the right horse for the right course" is relevant.

Of concern are some of the most widely propounded benefits of BRT. The newness of the mode has meant that insufficient experience has been gained to verify these claims. Some of these benefits require careful consideration, as they may be some of the strongest reasons for not introducing the mode. "Benefits" that require caution are:

- flexibility,

- ease of implementation,

- low cost, and

- implementation speed.

\section{Flexibility}

Flexibility of routing was one of the key motivations for the move away from the streetcar systems that were prevalent worldwide during the first half of the 20th century. The ability to avoid congestion and to change routes in response to new developments was a major factor in the growth of the diesel-driven motor bus. While the streetcar system was beset with reliability problems, the move to the diesel coach resulted in the loss of a number of collateral benefits that were 
implicit in the streetcar. One of the principal benefits of streetcar operations was the system's permanence.

During the era of the streetcar, the transit route was a clear demarcation of the major thoroughfare of the community, providing an axis on which the urban core could develop. It was obvious how transit users entered the area and developers responded by orientating buildings toward the transit routes to maximize their exposure. In contrast, the introduction of the diesel bus provided flexibility of routing. This flexibility also made it easier for the bus route to be relocated should traffic congestion become insufferable at a particular location. The introduction of the diesel bus also gave the route planner the flexibility to adjust route alignments to respond to development trends.

However, this flexibility affects the perception of the transit service. The reasons for the difference in perception are unclear; however, the resultant bias toward rail-based systems is well documented.

In addition, when the transit route has permanent infrastructure along a corridor it becomes part of the urban structure, which has to be "worked around" rather than merely relocated.

\section{Ease of Implementation}

Much has been written about the ease of implementation of bus systems over rail systems. In rail-based operations, it is necessary to relocate underground utilities due to corrosion and maintenance. The need to relocate utilities is a cost element that can consume a considerable part of the budget. If the project estimates are reasonable, though, they will be unlikely to impact the ease of implementation. When it comes down to it, the component that complicates the introduction of a rail-based system is the same as would complicate a complete BRT system: right-of-way. BRT enables a community to reserve rights-of-way before congestion is a major problem and roadway capacity expansion is no longer possible. But the task of reserving these areas is not easy. In situations where congestion has not reached intolerable levels, it is difficult for a community to understand the need to provide additional transit capacity, particularly when the general public sees few people using transit or when congestion levels are so low that there is little incentive to use transit. In communities that have experienced 
high levels of congestion in other corridors and have developed mass transit solutions, this is less of an issue.

The use of "eminent domain" or other involuntary land acquisition methods for the purchase of rights-of-way for a BRT project are more difficult to justify to the public. The use of such land acquisition methods may be subjected to legal challenge and, at a minimum, will result in negative media coverage.

Because of their large price tags, rail-based systems tend to enjoy more political support, which is very useful when public reception is less positive. This lack of political mass that most bus-based systems experience can make the most nonsensical concern an issue.

\section{Low Cost}

In an era of increased competition for federal funds, any means that allow for more efficient distribution of funds among a large number of communities is clearly attractive. BRT provides such an opportunity.

If BRT is going to be financially accessible to a large number of communities, it must be affordable. This will generally require communities to deploy lower-cost, proven technologies. Depending on the design of the system, the cost can be as low as 10 percent of an LRT system. Few communities have the resources to research and test new technologies so the components should be "off-the-shelf."

As it is not necessary to relocate underground utilities or provide an external power source, a BRT system could be constructed for far less than a comparable LRT system, while providing similar performance. BRT's low cost can also extend into service provision. With no overhead wires to maintain or tracks to grind, maintenance costs are reduced. Also, the use of dedicated lanes reduces the wear and tear on the vehicles, as traffic conditions are predictable and fewer emergency braking situations are likely to occur.

How can low cost be detrimental to the development of the system? While it is not so much the perception that the more we pay the better the product must be (although that does play into the equation), this is the political effect of a lowprice alternative. Undoubtedly, the bigger the price tag the more attention an item is given. Few bus-based systems can afford to build a statue of a politician along 
the route, so the project tends to attract little attention. Most critical is the need for a political champion. There are a number of times during the development of the project where a committed political proponent is essential. Without such an advocate, the project can languish in a maze of additional information needs with no one willing to shepherd the decision-makers to a decision.

The motivation behind the introduction of BRT needs to be clearly communicated. In some communities that already have an established rail system, BRT has been proposed as an alternative to the expansion of the existing system. Public reaction to such proposals has been particularly hostile, as community members perceive the relatively new concept of BRT as an inferior alternative. In many cases, the BRT alternative has been motivated by lack of funding and is promoted as the only affordable alternative.

\section{Implementation Speed}

The general perception within the transit industry is that the introduction of BRT service is similar to redesigns of service that transit providers do on a regular basis. The primary focus is on ensuring service delivery elements, such as schedule, operator, and route. This gets back to how BRT is defined. If the application of BRT is more akin to an "express bus," the above service delivery elements will suffice. However, if the desire is to create a service that mimics a typical light rail system, then the process is more complex. Essentially, if federal funds are utilized, the process for a release of the funding and the associated approval process are identical. During some of the earlier BRT projects, it was considered acceptable to undertake a less thorough environmental process. The extents of project impacts are now more fully understood and a more rigorous Environmental Impact Statement (EIS) must be produced, rather than an Environmental Assessment (EA).

The absence of a political champion can also impede the local decisionmaking process. The lack of political will to move a bus-based project with little in the way of political collateral benefit can extend project approval over what would normally be expected of a larger project.

As most BRT projects are relatively low cost, there are many funding options available that can reduce the reliance on federal monies and the processes attached to acquiring them. Also, the reduced infrastructure needs lessen some of the design complexities. 


\section{Further Considerations}

For BRT to be successful, a number of obstacles must be cleared before the mode can reach its full potential. Economists have shown that many factors contribute to transit use. This section examines three of the more pertinent factors associated with the success of a BRT system. The first two, poor image of the bus and rail-like vehicles, are qualitative variables not accounted for in consumer choice models. The third factor, exclusive rights-of-way, while directly quantifiable, also impacts the public's perception of the mode.

\section{Poor Image of Bus}

During a public meeting a citizen once described bus transit as "for people who not only didn't own a car but don't even know anyone who owns one." This perception that bus riders have no other alternative is fairly widely held. The use of terms such as "loser cruiser" by teenagers to describe conventional bus services reinforces the view that the private automobile is the only form of motorized transportation worth considering. One constant concern raised by transit professionals is the poor public image of the bus. While there are probably a number of examples of unmaintained equipment, dirty, poorly operated systems, the inferior perception of the mode is more ingrained into society than we think. The public image is cultivated at a young age, an example being in children's books where the rail or cable car is depicted as being a clean friendly mode whereas the bus is pollution producing, nasty, and dirty (Burton 1997). Increased public awareness of environmental issues has focused attention on the dieselpropelled vehicle with emissions directly in the operating area. Recent improvements in the efficiency of the diesel engine have largely gone unnoticed by the general public, as it seems that no matter how environmentally friendly a vehicle may be, the negative images conjured up by the word "diesel" are difficult to overcome. However, improvements in engine technology have been relatively recent and available budgets have not allowed operators to change their older, less environmentally friendly vehicle. The introduction of more efficient engine technology tends to occur over an extended period as most buses have an operating life in excess of 12 years. 
To overcome this bias, BRT services should endeavor to differentiate themselves from conventional bus services as much as possible. Several key factors distinguish the two service concepts. These factors either reduce delays or elevate the perception of a higher-quality service.

The general perception that buses are very slow is reinforced by the fact that motorists are held up by buses loading passengers. By removing the bus from the travel stream, the perception of constantly passing buses is reduced. Further exasperating the situation is the misguided belief that the more access points to the service, the greater the ridership. The increased number of stops, rather than attract users, serves to frustrate those passengers already onboard. It has been demonstrated with the introduction of light rail systems that passengers are prepared to walk further to obtain a higher level of transit service.

\section{Rail-like Vehicles}

Clearly the traveling public reacts differently to rail vehicles than they do to conventional buses. During the last 20 years, rail-based systems have been successful in attracting the choice rider. Barring the development of the low-floor vehicle, the conventional bus has not varied in appearance since its inception. Other factors, such as vehicle length, occupancy, capacity, engine capacity, and supplier track record, have driven the vehicle selection process. The look of the vehicle was not considered an important attribute. Still today, many senior-level managers of major transit agencies believe vehicle look is not an important attribute and that service is paramount to the passenger. While service is critical and usually a poor experience will not bring a consumer back, it is the attractiveness of the vehicle that initially "brings them through the door." As many marketing professionals note, the most difficult task is getting the customer to try a product in the first place. Once they experience the product, it is the service that maintains the consumer's interest.

Bias toward rail-based service is well established and is utilized in the transportation process by modelers. The exact reason for this bias in unknown; however, there is a series of factors that contribute to it. These factors relate to the service rather than the vehicle and tend to include the directness, simplicity, ease of use, and the general perception of being fast. 
Acquisition of a rail-like vehicle is a more difficult task than originally thought. While European manufacturers have responded directly to this need, U.S. manufacturers have not. Restrictions on the procurement of European-built vehicles in the form of "Buy America" legislation and federal vehicle testing requirements only add to the frustration of the proposed BRT operator.

\section{Exclusive Rights-of-Way}

Of all the elements that make up a BRT system, it is the exclusive right-ofway that causes the most controversy. This attribute most directly impacts the individual property owner. The effects can range from restrictions of on-street parking to the acquisition of frontage. Even in communities with high public transportation usage, impacted community members will challenge the need for right-of-way expansion for the development of a transit system. The situation is further complicated by poor public perception of the bus. The public seems willing to make more accommodations for a rail-based system than for a bus-based system. Part of the problem can be traced to the amount of nontransit improvements that accompany a project. These improvements include landscaping, public art, and bicycle and pedestrian facilities. Typically the size of associated nontransit improvements has been larger with a rail project than with a bus project. Bus-based projects tend to focus on service provision alone. In the overall scheme, a 1 percent public art budget in a rail project results in far more visible community products than a similar percentage in a lower-cost bus-based project.

While the allocation of exclusive rights-of-way is challenging, it is a key attribute of BRT. In addition to providing a number of service benefits, such as reducing travel times and improving reliability, its principle benefit is in the statement a community is making with respect to public transportation. The exclusive right-of-way renders a sense of permanence to the system and signals to the development community that high-quality transit will be available into the future.

The degree of exclusive rights-of-way depends on the environment in which the BRT facility is being located. The more exclusive the facility, the greater the impact. Facilities that are physically protected from entry of nonauthorized vehicles offer the most benefit to the BRT service. Extreme care should 
be taken not to bifurcate the community so that it is inconvenient for movement across the facility. The widening of an existing facility may result in a facility that is out of scale with the surrounding area, adding more impervious surface and transforming a collector-type street into a street that feels like a major arterial. Removal of on-street parking can have a similar impact on the "feel" of an area, by eliminating the collateral traffic-calming benefits. In positioning a BRT facility in an existing street environment, median running systems are most desirable from an operational and perception standpoint. Median lanes tend to set transit apart from the rest of the transportation system and clearly differentiate it from conventional bus services. The major concern relating to median locations is passenger access, as all access requires crossing at least part of the street. If vehicular access across and into the BRT facility is controlled, then higher operating speeds are possible. A median-operating arrangement also makes it possible for the number of bus lanes to be reduced in constrained areas. Curbside bus lanes are less efficient, as access to adjacent driveways must be maintained and BRT vehicles experience considerable delays as a result. Also, enforcement of curbside bus lanes is difficult from both a recognition and apprehension point of view.

\section{Conclusions}

Few transportation planners believe that we can build enough road infrastructure to fully meet the demand for private automobile travel. Most professionals believe that a balanced transportation system of private automobiles, transit, bikes, and pedestrians is the most reasonable solution. However, if transit is to provide the much-needed relief to our congestion problem and be considered a viable alternative to the automobile, then it must attract the choice rider. It has been demonstrated that choice riders are attracted to rail-type transit systems, therefore BRT systems must endeavor to mimic the positive characteristics of these services.

Although BRT provides an opportunity for transit providers to supply a higher level of service than a conventional bus service, BRT is not the panacea to all our transport ills. Being a relatively new mode, the public has had little opportunity to experience it and are still defining it by previous 
experiences of conventional bus services. BRT has a long way to go to prove itself as a viable mode to the general public. Although BRT offers the promise of meeting a range of travel needs, planners must be aware of its limitations in order to not raise false expectations.

\section{References}

Arnott, R., and K. Small. 1994. The economics of traffic congestion. American Scientist 82: 446-455.

Burton, V. L. 1997. Maybelle the Cable Car. New York: Houghton Mifflin.

\section{About the Author}

Graham N. CaReY (graham.carey@ltd.lane.or.us) is the project engineer for Lane Transit District's BRT project. In serving this project, Mr. Carey is responsible for all technical aspects of the BRT project. His primary professional focus is in the planning and design of bus-based transit systems. Previously, he was general manager of JRH Transportation Engineering and director of the Johannesburg Transit District, South Africa. He is a registered Professional Engineer (PE), certified planner (AICP), and fellow of the Institute of Transportation Engineers (ITE). 